\title{
Kuzey Kıbrıs’ta Müzede Eğitim Çalışmalarının Değerlendirilmesi
}

\section{Fatma GíRíTL ${ }^{1}$}

\author{
KKTC Kültür Bakanlığ 1
}

\begin{abstract}
$\ddot{O}_{z e t}$
Bu araştırmanın amacl, 1950'li yıllardan itibaren gelişen ve günümüzde birçok ülkede yaygın olarak kullanılmaya başlayan müzelerin eğitim ortamı olarak kullanımının Kuzey Kıbrıs’taki uygulanabilirliğini belirlemekve bu alanda yapılacakçalışmalar için bir kaynakoluşturmaktır. Bumakalede, KKTC Turizm, Çevre ve Kültür Bakanlığı, Eski Eserler ve Müzeler Dairesi bünyesinde bulunan müzelerin yapılanması ile Kıbrıs Türk Eğitim Sistemi yapılanmasının, genel amaçları ve ilkeleri, müzede eğitim açısından değerlendirilmiştir. Ayrıca Illkokul Hayat Bilgisi ders programında 'müze' kavramının hangi konularda ve ne şekilde yer aldığına ilişkin bir inceleme yapılmıştır. Yapılan araştırma sonucunda, KKTC Eski Eserler ve Müzeler Dairesi ve bünyesinde bulunan müzelerde henüz eğitim birimlerinin kurulmamış olduğu ve çağdaş anlamda müzede ĕgitim çalışmaları yapılabilmesi için gerekli herhangi bir çalışmanın gündemde olmadiğı tespit edilmiştir. KKTC Ĕ̆itim Sistemi Yapılanmasına ilişkin yapılan araştırmada ise KKTC Ĕ̈itim Sisteminin, genel amaçlar ve ilkeler açısından müzede eğitim yaklaşımına uygun bir yapıda olmasına karşın, müzede eğitim çalışmasına yönelik herhangi bir çalışma veya projenin gündemde olmadiğı görülmüş̧ür. Okullarda müzede eğitim uygulamalarının yapılabileceği en uygun derslerden biri olarak düşünülen İlkokul 1, 2 ve 3. sinıf Hayat Bilgisi ders programında 'müze' kavramının yer almasına ilişkin yapılan taramada ise toplam $10 \mathrm{kez}$ 'müze' kavramına yer verildiği tespit edilmiştir. Ayrıca, ders programının etkinlikler bölümünde sadece iki kez müzeye gidilmesi gerektiğinin vurgulandiğı görülmüştür. Genel olarak Kuzey Kıbrıs’ta müzelerin bir eğitim ortamı olarak kullanılmasına ilişkin anlayışın yerleşmemiş olması önemli bir eksiklik olarak görülmektedir.
\end{abstract}

Anahtar Sözcükler: Müze eğitimi, hayat bilgisi ders programı, KKTC eğitim sistemi

\begin{abstract}
The purpose of this research is to determine the applicability of using museums in Northern Cyprus as a means for education and to constitute a source for further study in this field. In this article, the objective and principles of the structuring of Cyprus Education System and museums under the Office for Ancient Arts and Museums of Turkish Cypriot Ministry of Tourism, Environment and Culture, have been evaluated in terms of education in museums. In addition, a study was carried out on how and under what subjects the term "museum" appears in primary school social sciences curriculum. As a result of these studies it was observed that no educational units were yet formed in museums under the Office for Ancient Arts and Museums and that there was nothing on the agenda regarding a study on using museums as educational centers. In the research carried out on the structuring of the TRNC Education System it was observed that despite the suitability of education in museums in terms of objectives and principles of TRNC Education System, there have been no study or project on the agenda towards education in museums. In the study on how often the term "museum" appears in the curricula of 1st 2 nd and 3rd year social sciences courses in primary school (which seem to be the most suitable courses for application of education in museums) it was seen that the term "museum" appeared a total of 10 times. In addition in the activities program of the course syllabus it was emphasized that there should be only two visits to museums. That an understanding of using museums as a center and means of education in North Cyprus has not been formed yet is an important deficiency for North Cyprus.
\end{abstract}

Keywords: Museum education, Social sciences curriculum, TRNC Education System

1 Dr.,KKTC Kültür Bakanlı̆̆l, Kültür Dairesi. E-posta: giritlifatos@yahoo.com 


\section{Giriş}

Geçmişin geleneksel öğretmen merkezli ve sonuç odaklı eğitim anlayışı, yerini öğrencinin öncelenerek merkeze alındığı, süreç odaklı bir eğitim anlayışına bırakmıştır. Günümüzün çağdaş eğitim yaklaşımına göre, sonuç değil sonuca götüren becerilerin öncelenmesi gerektiği düşünülmektedir. Çağdaş öğrenme kuramının kapsamını Paykoç şu şekilde açıklar: 'Çağdaş öğrenme kuramına göre öğrenme, bireyin aktif olmasını, uygulama yaparken aynı zamanda uyguladıkları üzerinde düşünüp bunları anlamlı hâle getirmesini, dilini kullanmasını ve sosyal bir faaliyette yer almasını kapsamaktadır.' (Paykoç, 2003: 49). Kuşkusuz ki bu yaklaşım, eğitim etkinliklerinin, keşfedici, yaşantısal ve bireyin yaratıcılığını ön plana çıkartan etkinliklerle donatılması ve buna bağlı olarak öğrenme ortamlarının da aynı doğrultuda geliştirilmesi gerekliliğini de beraberinde getirmektedir.

Buna paralel olarak eğitim alanında olduğu gibi müzecilik alanında da yaşanan gelişmeler sonucunda, geleneksel içe kapalı müzecilik anlayışının yerini, çağdaş, dışa açık bir yapıya bırakmış olduğu gözlemlenmektedir. 19. yy ortalarında kurumlaşarak, 20. yy ortalarına kadar gelen modern müzecilik yaklaşımının, nesneleri toplama ve sergileme temeline dayanan otoriter yapıyı terk ederek, 20. yy'ın ikinci yarısından itibaren gelişmeye başlayan post-modern müzecilikle birlikte, ziyaretçi ile karşılıklı bir iletişimin vurgulandığı yeni bir yaklaşımın benimsendiğini görüyoruz.

Müzede eğitimin, 1950'li yıllardan itibaren gelişmeye başlayan ve müzecilerle eğitimcilerin işbirliği sonucunda ortaya çıkan, belli bir felsefe ve yönteme dayalı bir yaklaşım olduğu bilinmektedir. Bir eğitim ortamı olarak düşünüldüğünde müzelerin, öğrenciyi harekete geçiren, yaparak, yaşayarak, üreterek, öğrenmeyi hızlandıran mekânları ile geleneksel eğitim anlayışının aşılmasında, önemli bir işleve sahip ortamlar olduğu görülmektedir (Onur, 2003a). Öğrenenin merkeze alınarak aktif kılındığı bir yaklaşımla dikkat çeken müzede eğitimin, çağdaş eğitim anlayışına uygun bir yapıda geliştiğini söylemek mümkündür. Müzede eğitimin temel ilkelerinden biri olan 'nesnelerden öğrenme' duyuları temel alan, yaşantıya dayalı ve yaratıcılı̆̆ önceleyen bir yaklaşımdır. Öğretimde nesnelerin kullanılmasının önemli etkilerine örnek olarak, nesnelerin yol açabileceği tartışmalar gösterilebilir. Bu tartışmalar sözcük dağarcığı, açıklık, görüş alış verişi, dinleme, yanıt verme ve benzeri becerilerin geliştirilmesinde etkili süreçlerdir (Hooper - Greenhill, 1999: 151). Bu gün birçok ülkede yaşam boyu öğrenme anlayışına uygun olarak müzelerde yapılan eğitimin, hem okul içi hem de okul dışı eğitimlerde kullanıldığını görmek mümkündür.

Müzede eğitim, eğitimciler ve müzecilerin birlikte çalışmasını gerektiren disiplinlerarası bir çalışma alanıdır. Kuzey Kıbrıs’taki müzelerin birer eğitim ortamı olarak kullanılabilmesi için öncelikle bir durum tespitine ihtiyaç olduğu düşünülmektedir. Bu çalışma ile Kuzey Kıbrıs’ta, müzede eğitim alanında uygulama yapılabilmesi için gerekli çalışmalar belirlenmeye çalışılmıştır. Günümüzde birçok çağdaş ülkede müzeler aktif öğrenme ortamı olarak kullanılırken; Kuzey Kıbrıs’ta bu alanda çalışmanın olmaması son derece üzücüdür ve önemli bir kayıptır. Ayrıca bu çalışma Kuzey Kıbrıs’ta müzelerin eğitim ortamı olarak kullanılması alanında yapılacak olan ilk araştırmalardan biri olması ve daha sonra yapılacak çalışmalara kaynak teşkil etmesi açısından önem taşımaktadır. Betimsel bir araştırma olan bu çalışmada öncelikle kaynak taramasına gidilmiş daha sonra da kaynak kişilerle bilgi alışverişinde bulunulmuştur. KKTC Millî Eğitim, Gençlik ve Spor Bakanlığı, Talim Terbiye Dairesi uzmanları ve KKTC Turizm, Çevre ve Kültür Bakanlığına bağlı Eski Eserler ve Müzeler Dairesi yetkilileri ile görüşme yapılmış ve açık uçlu sorularla bilgi alınmıştır. Araştırmada, KKTC’deki müzelerin bağlı olduğu Eski Eserler ve Müzeler Dairesi yapılanması ile Kıbrıs Türk Eğitim Sistemi yapılanmasının, genel amaçları ve ilkeleri, müzede eğitim açısından değerlendirilmiştir. Ayrıca en çok müzede eğitim uygulamalarının yapılabileceği düşünülen, İlkokul 1, 2 ve 3. sınıf Hayat Bilgisi programında 'müze' kavramının hangi konularda ve ne şekilde yer aldığına ilişkin inceleme yapılmıştır. 


\section{Müzelerin Eğitim Ortamı Olarak Kullanılması}

İlk olarak koleksiyonculukla var olmaya başlayan müzelerin, 19. yy ortalarında kurumlaşmaya başlarken, toplama ve sergileme temeline dayalı olarak geliştiği bilinmektedir. Müzelerin ilk kurumsallaştığ 1 dönemlerdeki amaçlarından biri olan sergilemenin temelinde yatan düşüncenin, ziyaretçileri bilgilendirme, sergilenen objelere ilişkin işlevsel, kronolojik, yapısal bilgi sunma veya tanıtma amacı olduğu düşünüldüğünde, doğal olarak bir eğitim sürecinin varlığından da söz edildiği görülmektedir. Sergileme amacı çerçevesinde ortaya çıkan bu süreç, belli bir amaca yönelik olmadan ve plansız olarak gerçekleşen bir eğitim süreci olarak da tanımlanabilir. Müzelerin, ilk kuruldukları dönemlerdeki belli bir aristokrat kesime hitap eden, otoriter ve geleneksel yapıların1, 20. yy'ın ikinci yarısından itibaren terk etmeye başladıkları görülmektedir. Böylece yeni yüzyılda, çağdaş ve demokratik bir yapıyla kendini yenileyen müzelerin, toplumla iletişim kurma hedefini öncelikli amaçları arasına almasıyla birlikte eğitim unsurunun da belirgin bir biçimde ön plana çıktığını görüyoruz. Günümüzün çağdaş müzeleri artık birer yaygın eğitim kurumu olarak halkı eğitmeyi, kültür ve bilimi topluma aktarmayı hedeflemekle birlikte, iletişim ve halkla ilişkiler yöntemlerini de aktif olarak kullanma yönüne gitmektedirler. Böylelikle çağa uygun olarak kendini yenileyebilmiş günümüz müzeleri, bir ailenin tüm fertlerinin eğlenerek öğrenebileceği bir araştırma merkezi, açık üniversite, eğitim ve kültür kurumu olarak hizmet vermektedirler (Atagök, 1999: 131).

Buna paralel olarak her alanda olduğu gibi eğitim alanında da çağın gereksinimlerine göre yenilenme ihtiyacı gündeme gelmiştir. Eğitim alanındaki değişim gözlemlendiğinde, son dönemlerde müzelere benzer bir biçimde, eğitim sistemlerinin otoriter yapıyı terk ederek demokratik bir yapıyı benimsediğini, geleneksel eğitim yaklaşımlarının yerini çağdaş, öğrenci merkezli ve demokratik bir eğitim yaklaşımına bıraktığ 1 görülmektedir.

Eğitimin geçmişteki amacı, bilgi ve beceri kazandırarak, çocuğu yetişkin dünyasına hazırlamak iken, günümüzde ihtiyaç duyduğu bilgi ve beceriyi nerede ve nasıl kazanabileceğine ilişkin rehberlik etmek, sürekli değişen toplum koşullarına uyum sağlayabilecek ve her türlü soruna yeni çözümler getirebilecek bireyler yetiştirmek olarak değişmiştir. Günümüz koşullarında artık bireydeki yaratıcılığ 1 keşfederek geliştiren ve eğitim ortamlarının çocuğa uygun şekilde düzenlenerek çocuktaki gizli güçlerin ortaya çıkartılabileceği, yaratıcılığın geliştirilebileceği bir eğitim anlayışına ihtiyaç vardır (Razon, 2013). Çağdaş eğitim yaklaşımlarıyla ön plana çıkan öğrencinin aktif olma gerekliliği ve görsel malzemelerle nesnelerin eğitim yöntemi olarak benimsenmesi, müzelere farklı bir boyut kazandırmıştır. Geçmişe ait kültürel değerleri ve nesneleri barındıran müzeler, artık öğrencilerin yaparak - yaşayarak öğrenmesine katkıda bulunabilecek, çağdaş eğitim yaklaşımına uygun, ideal eğitim ortamları olarak görülmeye başlamıştır. $\mathrm{Bu}$ durum ise müzecilerle eğitimcilerin birlikte çalışmasını, diğer bir deyişle iki alan arasındaki işbirliğinin başlatılmasını beraberinde getirmiştir.

Günümüzde okullara yönelik eğitim programları hazırlamak, müzelerin eğitim birimlerinin temel görevlerinden biri olarak kabul edilmekte ve pek çok ülkede müze-okul işbirliği yapılarak ve uzmanlar tarafindan hazırlanan eğitim programları ve materyallerle, okulların belli derslerini müzede yapabilmelerine imkân tanınmaktadır (Tezcan, 2003: 35, Onur, 1999: 5). Aynı zamanda müzecilik alanına da yeni bir ivme kazandıran bu durum sonucunda, çağdaş müzecilik anlayışını benimseyen müzelerde, eğitim birimlerinin ve eğitim atölyelerinin açıldığını görüyoruz. Türkiye'deki Ankara Anadolu Medeniyetleri Müzesi, İstanbul Modern, Kars Müzesi ve Almanya’daki Schönberg Gençlik Müzesi (Zwaka, 2007: 35), Amerika'daki MOMA bu bağlamda çalışmalarını yürüten müzelerden bazılarıdır.

Formal eğitimle sınırlı olmayan ve yaşam boyu süren bir eğitim anlayışını benimsemiş olan müze eğitimi, düşünmeyi geliştiren ve eğlenerek öğrenmeyi içeren bir yapıdadır. Müzede yapılan eğitimin önemli özelliklerinden biri ise düş gücüne, duyulara, estetik duyarlılığa, eleştirel ve yaratıcı yaklaşıma 
dayanmasının yanı sıra, yaşantıya dayalı bir öğrenme türü olup eğlenme kavramıyla da yakından ilişkili olmasidir.

Temelde 'nesnelerden öğrenme' anlayışına dayanan müzede eğitim yaklaşımında, müze koleksiyonları ile hedef kitle arasında sağlam bir ilişki kurulması beklenir (Onur: 2003b: 12). Genel olarak müzelerin eğitim ortamı olarak kullanılmasının, müze öncesinde, müzede ve müze sonrasında yapılacak, birbiriyle ilişkili bir dizi etkinlikten oluşan 3 temel bölüme ayrıldığı görülmektedir. Aynı zamanda tüm bu etkinliklerin, öğrencilerin yaş gurubu, beceri ve kazanım unsurları göz önünde bulundurularak hazırlanması beklenmektedir.

Müze Öncesi: Gidilecek müzeye ilişkin organizasyonun yapıldığı, öğrencilerin ilgisini çekecek ve müzeye ilişkin merak uyandıracak biçimde tasarlanmış olan etkinliklerin planlanarak uygulandığı bir nevi hazırlık sürecidir.

Müzede: $\mathrm{Bu}$ bölüm, müzeye gidilmeden önce tasarlanarak programlanmış, öğrencilerin duyularına hitap eden ve alternatiflere açık etkinliklerin müzede uygulandığı bölümdür. Bu bölümde genellikle müzenin tüm bölümlerinin gezilmesine gerek duyulmamakla birlikte, önemli olan belli bir nesne, belli bir dönem veya belli bir düşünceye odaklanmış, eğlenceli, eğitici, yaratıcılığg kışkırtan ve düşünmeye olanak sağlayan etkinliklerin yapılmış olmasıdır.

Müze Sonrası: Değerlendirme niteliğinde olan bu bölüm, müzede yapılan çalışmaların ürünlerinin ortaya konulduğu, sembolik ürünlerin ve müzeye ilişkin tartışmaların yapıldığı uygulamalara yer verilen bölümdür.

Çağdaş eğitim alanında son yıllarda Türkiye, İngiltere, Amerika, Almanya ve birçok Avrupa ülkesinde ortaya çıkan görüş ve düşüncelere baktığımızda, müzelerin okul dışı etkinliklerde, kullanılabilecek ideal öğrenme ortamları olarak kabul gördüğünü söyleyebiliriz. Müzecilik ve eğitim bilimleri alanlarının ortak çalışma anlayışının gelişmesiyle birlikte, müzelerin etkin kullanımını içeren, müzeden hareketle ve müze yoluyla öğretmek olarak da tanımlanabilen 'müze pedagojisi' alanı da gelişmeye başlamıştır (Adıgüzel, 2000: 132). Müze eğitim bilimi, en başta müzeyi bir kültür merkezi olarak algılar ve tanımlar (San, 2000: 7). Tüm bu gelişmeler sonucunda gelinen noktada müzelerde, müze eğitimine yönelik ayr1 bir alt uzmanlık alanı oluşurken, eğitim kurumlarında da müzede eğitim yaklaşımına ilişkin müze pedagojisinin yeni bir uzmanlık alanı olarak ortaya çıktığı görülmektedir.

Türkiye eğitim sistemine bakıldığında, 2000'li yıllarda Millî Eğitim Bakanlığı tarafından yapılan değişikliklerle yapılandırmacı yaklaşımın benimsendiğini ve 2005 - 2006 öğretim yılından itibaren eğitim programlarında yapılan değişikliklerle bazı derslerde müzelerden yararlanılması gerektiğinin vurgulanmaya başladığını görüyoruz. Bu çerçevede yenilenen sanat etkinlikleri ve görsel sanatlar ders programlarında müze eğitimi, öğrenme alanı olarak ilköğretim birinci sınıftan sekizinci sınıfa kadar, programın yaklaşık üçte birini oluşturacak şekilde düzenlenmiştir (İlhan, 2010: 43). Diğer bir taraftan öğretmen yetiştiren lisans programlarında da müze eğitimine yaygınlıkla yer verildiği görülmektedir. Ayrıca Ankara Üniversitesinde 1997 yılında kurulan Müze Eğitimi Ana Bilim Dalı, lisansüstü düzeyde donanımlı müze eğitimi uzmanları yetiştirmektedir. $\mathrm{Bu}$ gelişmelere paralel olarak Türkiye'deki müzelerde de eğitim birimleri ve atölyelerin kurulmaya başladığı görülmektedir. Müzelerin bünyesinde kurulan eğitim birimleri, üniversite ve okullarla iş birliği içerisinde çalışarak, müze eğitimine yönelik çeşitli projeler gerçekleştirmektedirler.

\section{KKTC Eski Eserler ve Müzeler Dairesi Yapılanmasının, Müzelerin Eğitim Ortamı Olarak Kullanılması Açısından Değerlendirilmesi}

Kuzey Kıbrıs Türk Cumhuriyeti’nin, eski eserler açısından son derece zengin ve M.Ö. 7000 yılından 
günümüze kadar gelen, geniş bir kültür mozaiğini barındıran bir coğrafyaya sahip olduğu bilinmektedir. Doğu Akdeniz' in ortasında yer alan ada, geçmişte önemli bir ticaret merkezi olmasından da kaynaklı olarak, birçok kez el değiştirmiştir. Tarih boyunca çeşitli uygarlıklara ev sahipliği yapan Kıbrıs adası, her uygarlığın ada topraklarında kendinden bir şeyler bırakarak ayrılması sonucunda, son derece zengin bir kültür mirasına sahiptir. Coğrafi olarak küçük olmasına rağmen eski eser ve ören yerleri bakımından zengin olan Kuzey Kıbrıs'ta, ören yerleri ve müzelerin bağlı olduğu Eski Eserler ve Müzeler Dairesi, Turizm Çevre ve Kültür Bakanlığg çatısı altında faaliyetlerini yürütmektedir. KKTC, Eski Eserler ve Müzeler Dairesi, Röleve ve Restorasyon Şubesi, Müzeler ve Ören Yerleri Şubesi ve Kazı İşleri Şubesi olmak üzere 3 ayrı şubeden oluşmaktadır. Ayrıca, Eski Eserler ve Müzeler dairesine bağlı olarak çalışan Lefkoşa, Gazi Mağusa, Güzelyurt ve Girne olmak üzere 4 tane Müzeler ve Ören Yerleri Bölge Şube Amirlikleri bulunmaktadır.

Eski Eserler Dairesinden alınan bilgiye göre Kuzey Kıbrıs’taki müzeler; millî müzeler, kilise manastır müzeleri, ikon müzeleri, etnografik müzeler, taş eserler ortaçağ müzeleri, arkeolojik müzeler ve güzel sanatlar müzeleri olmak üzere 7 farklı içerikle sınıflandırılmışlardır. Bugün itibarıyla KKTC Eski Eserler ve Müzeler Dairesine bağlı bulunan toplam 34 müzenin bölgelere göre dağılımı ve içerikleri Tablo-1'de görüldüğü gibidir. Müzelerin gözetim, denetim, ziyarete açılması, kurulması ve geliştirilmesi ise ilgili daire müdürlüğünün görevleri arasındadır. Eski Eserler ve Müzeler Dairesine

Tablo 1. KKTC Eski Eserler Dairesine Bă̆lı Müzelerin İçerik ve Bölgelere Göre Dă̆ılımı

\begin{tabular}{|c|c|c|c|c|c|c|c|c|}
\hline Bölgeler & $\begin{array}{l}\text { Müze } \\
\text { sayısı }\end{array}$ & Milli & $\begin{array}{c}\text { Kilise } \\
\text { Manastır }\end{array}$ & İkon & Etnoğrafik & $\begin{array}{c}\text { Taş } \\
\text { Eserler } \\
\text { Orta Çağ }\end{array}$ & Arkeoloji & $\begin{array}{c}\text { Güzel } \\
\text { Sanatlar }\end{array}$ \\
\hline $\begin{array}{c}\text { Lefkoşa } \\
\text { Bölgesi }\end{array}$ & 7 & 2 & - & - & 3 & 2 & - & - \\
\hline $\begin{array}{c}\text { Güzelyurt } \\
\text { Bölgesi }\end{array}$ & 2 & - & - & 1 & - & - & 1 & - \\
\hline $\begin{array}{c}\text { Gazi } \\
\text { Mağusa } \\
\text { Bölgesi }\end{array}$ & 9 & - & - & 4 & 2 & - & 3 & - \\
\hline $\begin{array}{l}\text { Girne } \\
\text { Bölgesi }\end{array}$ & 16 & 2 & 1 & 2 & 2 & 4 & 4 & 1 \\
\hline Toplam & 34 & 4 & 1 & 7 & 7 & 6 & 8 & 1 \\
\hline
\end{tabular}

bağlı bulunan müzelerin içerikleri incelendiğinde, Kuzey Kıbrıs’taki müzelerin çoğunlukla arkeoloji, ikon ve etnoğrafya müzeleri olduğu görülmektedir. En az görülen müze türü ise kilise manastır müzeleri ile güzel sanatlar müzeleridir. Müzelerin ziyarete açılış tarihleri incelendiğinde ise, 04.03.1963 y1lında ziyarete açılan ilk müzenin, Lefkoşa'daki Mevlevi Tekke Etnoğrafik Müzesi, en son ziyarete açılan müzenin ise yine Lefkoşa'da 07.09.1995 tarihinde açılan, Bedesten Ortaçağ - Mezar Taşları Müzesi (Heykel Atölyesi) olduğu görülmektedir.

Yetkililerden alınan bilgiye göre Eski Eserler Dairesi denetim ve gözetimindeki müze ve ören yerleri, daire müdürlüğüne bağlı bulunan Bölge Şube Amirlikleri tarafindan yönetilmekte olup müze veya ören yerlerine özel, yöneticilik veya müdürlük kadroları bulunmamaktadır. Genel olarak küçük ölçekli yapıya sahip olan KKTC müzelerinde, görevli bulunan personel genellikle bekçilik veya gişe sorumluluğu ile görevlendirilmiş çalışanlardan oluşmaktadır. Yine yetkililerden alınan bilgilere göre, 
daire kadrolarında görev yapan sanat tarihçisi ve arkeologlar, sadece bölge şube amirliklerinde ve Eski Eserler Dairesinde görev yapmaktadırlar. Ayrıca KKTC'deki müzelerde eğitim birimleri veya eğitim atölyelerinin oluşturulmasına yönelik herhangi bir çalışma henüz gündeme gelmemiştir.

Müzelerin eğitim ortamı olarak kullanılması açısından bakıldığında KKTC'deki Eski Eserler ve Müzeler Dairesine bağlı bulunan müzelerin çağdaş müzecilik anlayışına uzak bir örgütlenme yapısı ile yönetildiğini söylemek mümkündür. Günümüzde çağdaş anlamda kendini yenileyen her müzede bir eğitim biriminin ve müze eğitimi sorumlusunun olması beklenmektedir. Müzelerin koleksiyonları ile ilişkili olarak hazırlanması gereken, farklı yaş gruplarına yönelik eğitim programları ile müze hizmetlerinin geliştirilmesi, günümüzde önemli bir müzecilik hizmeti olarak görülmektedir. KKTC'deki müzelerde henüz eğitim çalışmalarının yapılmasına yönelik herhangi bir hazırlık olmamasına rağmen müzelerin bazılarının gerek mekân gerekse içerik açısından eğitim ortamı olarak kullanılmaya son derece uygun olduğu düşünülmektedir. Örneğin ilk akla gelen Güzelyurt Arkeoloji ve Doğa Müzesi ile Girne Kalesi ve Seksiyonlarının müzede eğitim açısından kullanılmaya müsait bir mekân ve içeriğe sahip olduğu söylenebilir.

KKTC Yakın Doğu Üniversitesi, Atatürk Eğitim Fakültesi, Okul Öncesi Öğretmenliği bölümünde, 2005 - 2006 öğretim yılından itibaren, Ankara Üniversitesi, Sosyal Bilimler Enstitüsü, Müze Eğitimi Ana Bilim Dalı Başkanı Prof. Dr. Ayşe Çakır İlhan tarafından yürütülen, Yaratıcılık ve Yaratıcı Çocuk Etkinlikleri dersi kapsamında, öğretmen adaylarına yönelik müzelerin eğitim ortamı olarak kullanılmasına ilişkin uygulamalı müze eğitimi etkinlikleri yaptırılmaya başlanmıştır. Buna ek olarak yine aynı bölümde Prof. Dr. Ayşe Çakır İlhan'ın yürüttüğü drama dersi kapsamında, 2007 Nisan ayında Yakın Doğu Üniversitesi Müzesinde açılan 'Leonardo: Evrensel Deha' sergisinde uygulamalı drama etkinlikleri yaptırılmıştır. Daha sonra YDÜ Eğitim Bilimleri Enstitüsü, Okul Öncesi Öğretmenliği programında yine Prof. Dr. Ayşe Çakır İlhan tarafindan verilen ‘Müze ve Eğitim’ adlı derse 15 kişi katılmış ve Kuzey Kıbrıs’taki müzelerde, lisansüstü düzeyde müze eğitimi uygulamaları gerçekleştirilmiştir. Ayrıca 2008 - 2009 öğretim yılında KKTC Atatürk Öğretmen Akademisi, Okul Öncesi ve Sınıf Öğretmenliği Bölümlerinde, Ankara Üniversitesi Eğitim Bilimleri Enstitüsü, Güzel Sanatlar Eğitimi Doktora öğrencisi olan Fatma Giritli tarafından yürütülen 'Kıbrıs Türk Kültürü' adlı ders kapsamında, Kıbrıs’taki müzelerin eğitim ortamı olarak kullanılmasına ilişkin uygulamalar gerçekleştirilmiştir. Son olarak Ankara Üniversitesi Eğitim Bilimleri Enstitüsü, Güzel Sanatlar Eğitimi Doktora öğrencileri Fatma Giritli ve Emine Kıvanç'ın Yakın Doğu Üniversitesi, Atatürk Eğitim Fakültesinde halen yürüttükleri lisans düzeyindeki derslerde, Kuzey Kıbrıs'taki müzelerin eğitim ortamı olarak kullanılmasına yönelik eğitim uygulamalarına yer verdikleri bilinmektedir.

\section{Kıbrıs Türk Eğitim Sistemi Yapılanması İçerisinde Müze Eğitiminin Yeri}

Kıbrıs Türk Eğitim Sistemi, 2005 yılında en son yenilendiği şekliyle ‘Temel Öğretim', ‘Orta Öğretim’ ve 'Yüksek Öğretim' olmak üzere üç ana dönemden oluşmaktadır. Bu yeni yapıya göre ‘Temel Eğitim' olarak tanımlanan dönem; Okul Öncesi, İlkokul ve Ortaokul dönemi olmak üzere 3 ana döneme ayrılmaktadır. KKTC Millî Eğitim Bakanlığı, Talim Terbiye Dairesinin 2005 Eylül ayında yayınladığı, yeni eğitim sistemini tanıtan kitapçıkta yer alan, yeniden yapılanmaya duyulan ihtiyaca ilişkin gerekçeler; Kıbrıs Türk toplumunun bilgi çağında diğer toplumlar arasındaki yerini alması, sosyal, kültürel, ekonomik alanlarda gelişmesi, eğitimde firsat eşitliğinden yararlanması ve yaşam boyu eğitim, değişime açık eğitim ve öğrenci merkezli eğitime olanak sağlanması şeklinde özetlenebilir.

KKTC Millı̂ Eğitim Bakanlığı, Talim Terbiye Dairesinin yayınladığı ‘Kıbrıs Türk Eğitim Sistemi’ adlı kitapçıkta, Kıbrıs Türk eğitim sisteminin yeniden yapılanma gerekliliği, yeni sistemin vizyonu misyonu ve hedeflenen 21.yy insan özellikleri incelendiğinde, yaşam boyu eğitim, değişime açık eğitim ve öğrenci merkezli eğitim ilkelerinin benimsenerek bireye çağdaş insan yeterliliklerinin kazandırılmasının 
öncelendiği görülmektedir. Aynı zamanda yeni sisteme göre, eğitimin öncelikli hedefleri arasında, öğrenci merkezli yapılandırmacı eğitim yaklaşımının benimsendiği vurgulanmaktadır.

Kıbrıs Türk eğitim sistemi kitapçığının, öğretim yöntem ve teknikleri bölümünde, öğretmenlerin, öğrenci merkezli öğretime uygun yöntemler kullanabilmeye yönelik olarak sürekli eğitilmesi vurgulanırken, öğretimde kullanılması önerilen yöntemler ise şu şekilde sıralanmaktadır: Oyun yöntemi, deney yöntemi, deneyim yöntemi, işbirlikçi yöntem, buluş yöntemi, gezi gözlem yöntemi, proje yöntemi, problem yöntemi, psikodrama yöntemi, ironi yöntemi, gösteri yöntemi, kooperatif yöntemi, soru - cevap yöntemi, araştırma yöntemi, tartışma yöntemi, düşün - eşleş - paylaş yöntemi, kısa yazılar yazdırma yöntemi ve beyin firtınası yöntemi.

Genel olarak bakıldığında müzede eğitim yaklaşımının Kıbrıs Türk eğitim sisteminin genel ilke ve yapısına uygun bir yaklaşım olduğu söylenebilir. Gerek benimsenen eğitim yaklaşımları gerekse önerilen eğitim yöntemleri incelendiğinde, sistemin genel ilkelerinin müzede eğitim yaklaşımı ve yöntemleri ile örtüştügü görülmektedir. Bununla birlikte Kıbrıs Türk Eğitim Sisteminin genel amaçlar ve yapılanmaya ilişsin açıklamalarında 'müze' kavramına yer verilmemiştir. Ayrıca Talim Terbiye Dairesi uzmanlarından alınan bilgiye göre, çağdaş anlamda müzede eğitim yaklaşımının okullarda uygulanabilmesine ilişkin herhangi bir çalışma henüz gündemde değildir. Buna ek olarak yine uzmanlardan alınan bilgiye göre okullardaki öğrenciler, öğretmenleriyle birlikte zaman zaman müze ziyaretlerine gitmekte fakat yapılan geziler geleneksel yöntemlerle ve öğretmenlerin inisiyatifinde yürütülmektedir. Özetle müzede eğitim uygulamalarına ilişkin herhangi bir plan, program veya proje henüz Talim Terbiye Dairesince ele alınmamıştır.

\section{Kıbrıs Türk Eğitim Sistemi İlkokul Programları ve İlkokul Hayat Bilgisi Ders Programının Müze Eğitimi Açısından Değerlendirilmesi}

Kıbrıs Türk Eğitim Sisteminin, ilkokul programlarında, öğrenci merkezli ve yapılandırmacı eğitim yaklaşımı çerçevesinde, eğitimde 'yaparak - yaşayarak öğrenme' ilkesine ağırlık verilmesi ve zihin gücü ile belleğin güçlendirilmesine yönelik etkinliklere yer verilmesi gerekliliği özellikle vurgulanmaktadır. Ayrıca ilköğretim programlarında, öğrencilerin olayları eleştirip sorgulamasına, okul içi ve okul dışı etkinliklere katılmasına olanak sağlanması gerektiği belirtilmektedir. Müzede eğitim açısından bakıldığında, ilkokul eğitim programlarında benimsenen eğitim yaklaşımlarının ve vurgulanan ilkelerin, müzede eğitim yaklaşımının temel ilkeleri ile örtüştügü görülmektedir (MEB).

İlkokul programlarındayer alan veen çokmüzede eğitimyapılmaya uygun olduğu düşünülen derslerden biri Hayat Bilgisi dersidir. Kıbrıs Türk eğitim sisteminde, ilkokul 1, 2 ve 3.sınıf ders programında yer alan Hayat Bilgisi dersi ile, öğrencilere kazandırılması hedeflenen beceriler şunlardır: Eleştirel düşünme, yaratıcı düşünme, iletişim, araştırma, problem çözme, karar verme, bilgi teknolojilerini kullanma, girişimcilik, Türkçeyi doğru, etkili ve güzel kullanma, gözlem, mekânı algılama, zaman ve kronolojiyi algılama, değişim ve sürekliliği algılama, sosyal katılım, empati, kaynakları etkili kullanma, güvenlik ve korunmayı sağlama, özyönetim. Hayat Bilgisi 1, 2 ve 3. sınıf ders programının felsefesinde ise dersin amacının, sosyal bir varlık olan çocuğun çevresinde olup biten olaylara ilgi duyması sonucunda ortaya çıkan merakının giderilmesi olarak belirtilmiştir. Ayrıca Hayat Bilgisi dersinin yaşama, deneme gözlem yapma ve iş ortaya çıkarma dersi olduğu da programın felsefesine ilişkin açıklamalar bölümünde yer almaktadır. Hayat Bilgisi dersi, müzede eğitim açısından değerlendirildiğinde, öğrencilere kazandırılmak istenen beceriler ve dersin felsefesinde yatan düşüncelerin, müzede eğitim yaklaşımının ilke ve amaçları ile örtüştüğü ve en çok müzede eğitimin kullanılması gereken derslerden biri olduğu düşünülmektedir.

KKTC'DE 2010-2011 öğretim yılında uygulamada olan, ilkokul Hayat Bilgisi derslerinde 1. ve 2. sinıflarda, Kuzey Kıbrıs'ta hazırlanan yerel program, 3. sınıfta ise Türkiye'de hazırlanan ilkokul 3. sınıf Hayat Bilgisi ders programı kullanılmaktadır. Kıbrıs Türk eğitim sisteminde, ilkokul 1, 2 ve 3. sınıf dersi olarak yer alan Hayat Bilgisi programında 'müze' kavramına hangi konularda ve ne şekilde yer 
verildiğine ilişkin yapılan taramada aşağıdaki sonuçlara ulaşılmıştır.

KKTC'DE hazırlanmış olan yerel Hayat Bilgisi 1 ve 2. sınıf ders programında, toplam 5 kez kullanılan 'müze' kavramı, programın en son bölümünde yer alan 'Belirli Gün ve Haftalar' konusu başlığı altında kullanılmıştır. Programda kullanılan 'müze' kavramı, kullanılış sırasına göre aşağıda görüldüğü şekilde yer almıştır.

'Belirli Gün ve Haftalar' konu başlığı kapsamında kullanılan;

1. '10 Kasım Atatürk'ün ölüm günü ve Atatürk Haftası: 10-16 Kasım' konusuna ilişkin,

Sarmal alt temalar bölümündeki,

Toplumsallık, milli duygular ve aitlik temasının konular ve kavramlar bölümünde 'Etnoğrafya Müzesi ${ }^{\text {’ }}$ kavramı kullanılmıştır.

Programda kullanılan ilk 'müze' kavramı, Atatürk haftası kapsamında yer alan, toplumsallık, millî duygular ve aitlik temasının konular ve kavramlar bölümünde sadece bir kavram olarak yer almıştır. Ayrıca bu bölümde kullanılan 'Etnoğrafya Müzesi' kavramına ilişkin herhangi bir kazanım veya etkinlik örneğine yer verilmemiştir.

2. 'Müzeler Haftası (18-24 Mayıs)' ${ }^{3}$ konu başlığında kullanılmıştır.

3. 'Müzeler Haftas1 (18-24 Mayıs)' konusunun,

Kazanımlar bölümünde;

'1. Müzelerin, sosyal yaşamdaki önemini ifade eder.'4 şeklinde kullanılmıştır.

4. 'Müzeler Haftas1 (18-24 Mayıs)' konusunun,

Etkinlikler bölümünde 'Müze Ziyaretleri'5 kavramı kullanılmıştır.

5. 'Müzeler Haftas1 (18-24 Mayıs)' konusunun,

Konular ve Kavramlar bölümünde 'müze' kavramı kullanılmıştır.

Programda kullanılan 2. , 3. , 4. ve 5. 'müze' kavramı, 'Müzeler Haftası' olarak belirlenen konu başlığında, ayni konuya ilişkin kazanımda, söz konusu kazanıma ilişkin etkinlikler bölümünde ve yine ayni konuya ilişkin konular ve kavramlar bölümünde birer kez kullanılmıştır. Ayrıca etkinlikler bölümünde belirtilen 'Müze Ziyareti' ile ilgili herhangi bir etkinlik örneği veya konuyla ilgili açıklamaya yer verilmemiştir.

KKTC'de yürürlükte olan ve Türkiye' de hazırlanmış olan İlkokul Hayat Bilgisi 3. sınıf ders programında, toplam 5 kez kullanılan 'müze' kavramı, programın son bölümünde yer alan 'Dün, Bugün, Yarın' teması kapsamında kullanılmıştır. Programda kullanılan 'Müze' kavramı, kullanılış sırasına göre aşağıda görüldüğü şekilde yer almaktadır.

'Dün Bugün Yarın' teması;

1. Kazanımlar bölümünde;

'C.3.24. Müzelerden? ve tarihi mekanlardan bir eğitim ortamı olarak yararlanır; nesnelerin müzelerdeki ${ }^{8}$ eski hali ile yeni halini karşılaştırarak zaman içindeki değişimi kavrar.’

2 KKTC İlkokul Hayat Bilgisi Program s: 90

3 Age s:94

4 Age s:94

5 Age s:94

6 Age s:94

7 Age s:202

8 Age s:202 
2. C.3.24'de belirtilen kazanıma ilişkin etkinlik örnekleri bölümünde,

'Müzeye9 Gidiyoruz: Müze' ${ }^{\mathbf{1 0}}$ veya tarihi mekan gezisi düzenlenir. Gruplar oluşturulur. Grupların müzedeki ${ }^{11}$ eserleri çeşitli yönlerden (tarz, biçim, görünüş, kullanım, renk, desen, büyüklük) incelemeleri sağlanır. Bulgularını, verilen çalışma kağıtlarına not ederler. sınıfta hem bulgular hem de nelerin, nasıl değiştiği tartışılır.'

İlkokul 3. sınıf Hayat Bilgisi Programında toplam 5 kez kullanılan 'müze' kavramı, 'Dün, Bugün, Yarın' olarak belirlenen son konu başlığı kapsamında yer almaktadır. 'Dün, Bugün, Yarın' başlıklı konu kapsamındaki bir kazanımda da iki kez kullanılan 'müze' kavramı, sözü edilen kazanıma ilişkin etkinlik örneğinde ise $3 \mathrm{kez}$ kullanılmıştır. Etkinlik kapsamında kullanılan 3 'müze' kavramının ilki etkinlik başlığında kullanılırken, geriye kalan iki kavram ise etkinlik açıklamalarında yer almıştır. Ayrıca C.3.24. kazanımın ifade edildiği cümlede, özellikle müzelerden ve tarihi mekanlardan bir eğitim ortamı olarak yararlanılması gerektiğinin ifade edilmiş olması, müzede eğitim açısından önemli bir yaklaşımdır.

Yukarda görüldüğü gibi KKTC'DE yürürlükte olan ve en çok müzede eğitim yaklaşımının kullanılması beklenen ilkokul 1, 2 ve 3. sınıf Hayat Bilgisi ders programında 'müze' kavramına toplam 10 kez yer verilmiştir. Ayrıca 'müze' kavramı program kapsamında sadece iki kez etkinlik olarak müzeye gidilmesi bağlamında kullanılmıştır.

\section{Sonuç}

Çalışmanın sonucunda, Kuzey Kıbrıs’taki Eski Eserler ve Müzeler dairesine bağlı bulunan müzelerde, henüz eğitim birimlerinin kurulmasına yönelik herhangi bir çalışmanın olmadığı ve genel olarak müzelerin yapılanmasının müze eğitimi yaklaşımına hazır olmadığı görülmüştür. Kıbrıs Türk Eğitim Sisteminin ise genel amaçlar ve ilkeler açısından müzede eğitim yaklaşımına uygun bir yapılanmaya sahip olmasına karşın, KKTC Milli Eğitim Bakanlığı tarafından müzelerin eğitim ortamı olarak kullanılmasına ilişkin herhangi bir çalışmanın henüz yapılmadığı tespit edilmiştir.

Kuzey Kıbrıs'taki müzelerin, eğitim çalışmaları için programlı bir yapılanma içerisinde olmamasına rağmen, müze eğitimi için uygun nesneleri barındırdıkları bilinmektedir. Ayrıca coğrafi olarak da küçük bir ülke olan KKTC'de müzelere ulaşımın kolay olması, müzelerin eğitim ortamı olarak kullanılması açısından olumlu bir unsurdur. Ancak müzelerde arkeolog, sanat tarihi ve müze eğitimi uzmanlarının olmaması ve genel olarak Kuzey Kıbrıs'ta müzelerin bir eğitim ortamı olarak kullanılmasına ilişkin anlayışın henüz yerleşmemiş olması bir eğitim adası olan Kuzey Kıbrıs için önemli bir eksiklik olarak görülmektedir. $\mathrm{Bu}$ eksikliğin en kısa zamanda giderilebilmesi için müze ve ören yerlerinin bağlı olduğu Eski Eserler ve Müzeler Dairesinde, bir eğitim şubesinin kurulmas1 ve müzelerde yapılacak tüm eğitim çalışmalarının, bu şubede görev alacak müze eğitim uzmanları tarafından, okullarla işbirliği içinde planlanması gerekmektedir. Buna ek olarak, her müze için çeşitli yaş gruplarına uygun olarak hazırlanmış müze eğitim yaprakları ve eğitim etkinliklerinin planlanması ve müzelerin hem örgün hem de yaygın eğitim anlamında, topluma hizmet eden çağdaş bir yapıya kavuşturulması gerekmektedir. Diğer bir taraftan Kuzey Kıbrıs’ta öğretmen yetiştiren kurumlarda, müzede eğitim yaklaşımına ilişkin konulara yer verilmesi ve Millî Eğitim Bakanlığı tarafından, okullarda görev yapan öğretmenlere yönelik olarak müzede eğitim yaklaşımına ilişkin hizmet içi eğitim seminerlerinin düzenlenmesi gerekmektedir. Genellikle birçok insanın ilk olarak okul gruplarıyla küçük yaşlarda ziyaret ettiği müzelerden, olumlu duygularla ayrılmasını sağlamanın bir yolu da, geleneksel müze ziyaretlerinde olduğu gibi müzelerin bir kapısından girip diğer kapısından çıkarak, hiçbir nesneye odaklanmadan ve öğrencilerle nesneler arasında bağ kurmadan, hızlıca yapılan gezi şeklindeki ziyaretlerden uzaklaşmaktır. Müze eğitimi yaklaşımının

9 Age s:202

10 Age s:202

11 Age s:202 
en önemli unsurlarından biri de, müze ziyaretlerinin eğlenceli ve çekici hale getirilmesiyle birlikte, toplumun müzelere olan ilgisinin artırılmasında etkili bir yaklaşım olmasıdır. Son olarak KKTC'de genel olarak müzelerin bir eğitim ortamı olarak kullanımına ilişkin anlayışın geliştirilebilmesi için, Turizm, Çevre ve Kültür Bakanlığı, Kültür Dairesi çatısı altında geliştirilecek konferans, sempozyum, bilgilendirme toplantıları ve etkinlik projeleriyle, toplumda konuya ilişkin farkındalık geliştirilmesine katkıda bulunulması gerekmektedir.

\section{Kaynaklar}

Adıgüzel, Ö. (2000). Müze Pedagojisinin Türkiye'deki Yansımaları ve Müzelerde Yaratıcı

Drama Uygulamaları. Üçüncü Uluslararası Tarih Kongresi - Müzecilikte Yeni Yaklaşımlar, Numune Matbaacilık, İstanbul.

Atagök, T. (1999). Yeniden Müzeciği Düşünmek. Yıldız Teknik Üniversitesi Yayınları, İstanbul.

Greenhill, Hooper, E. (1999). Müze ve Galeri Ĕgitimi. (Çev. Meltem Örge Evren, Emine

Gül Kapçı), Yay. Haz: Prof. Dr. Bekir Onur, Ankara Üniversitesi Çocuk Kültürü Araştırma ve Uygulama Merkezi Yayınları, No:4, Ankara.

İlhan, Ayşe.Ç. (2010). Türkiye’de Müze Eğitimi. Müze Eğitimi Seminerleri II, Ankara Üniversitesi Basımevi, Ankara.

KKTC Milli Eğitim ve Kültür Bakanlığı Talim Terbiye Dairesi (2005). Kıbrıs Türk Eğitim Sistemi, Devlet Basımevi, Lefkoşa.

MEB. (2013). Hayat Bilgisi Ders Programı. http://talimterbiye.mebnet.net/Ogretim\%20

Programlari/ilkokul/2010-2011/HayatBilgisi-1-2\%20(Yerel).pdf

MEB. (2013). Kıbrıs Türk Ĕgitim Sistemi. http://talimterbiye.mebnet.net/ktegitimsistemi.html

Onur, B. (1999). Müze Eğitimi ve Kültürel Kimlik. Ankara Üniversitesi, Sosyal Bilimler Enstitüsü Yayınları No:12

Onur, B. (2003a). Müze Ortamında Çocukla İletişim. http://ilef.ankara.edu.tr/ki/yazi php?yad=2092

Onur, B. (2003b). Müze Eğitimi: Temel Illkeler ve Politikalar. Müze Eğitimi Seminerleri - I.

Suna-İnan Kıraç Akdeniz Medeniyetleri Araştırma Enstitüsü, Antalya.

Paykoç, F. (2003). Türkiye'de Müze Eğitimi Uygulamalart: Tarihçe ve Örnekler. Müze Eğitim

Seminerleri - 1, Suna - İnan Kıraç Akdeniz Medeniyetleri Araştırma Enstitüsü, Antalya.

Razon, N. (2013) Yaratıcılĭ̆l Geliştirici Oyunla Ĕ̈itim. http://www.ekipnormarazon.com/ makaleler/37-yaraticiligi-gelistirici-oyunla-egitim?catid=11\%3Aoyun-ve-cocuk

San, İ. (2000) Müze Kültürü, Sanat Kültürü ve Toplumsal Sorumluluk. Müzeciler Derneği Yayını, Ankara.

Tezcan, K. (2003). Ĕ̈itim Ortamı Olarak Müzeler. Yıldız Teknik Üniversitesi Basım - Yayım Merkezi, İstanbul.

Zwaka, P. (2007). Müzeler Çocuklar ve Gençler Iç̧in Kültürel Mekânlar mı? Almanya'daki Durum.

Eğitim ve Müze Semineri. Kök Yayıncılık, Ankara. 


\section{Summary \\ Evaluation of the Studies on Museum Education in The TRNC Fatma GÍRITL ${ }^{1}$}

TRNC Ministry of Culture

\section{Introduction}

Former conventional teacher-centred and product-oriented education has been replaced with studentcentred and process-oriented education. In line with the modern educational approaches, it is a common thought that it is the skills leading to the product that should be prioritized, not the product itself. Conventional theory of learning was explained as follows by Paykoç: 'In accordance with the modern theory of learning, learning requires an individual to be active, to think over and make sense of his/ her actions while acting, use language and take part in a social activity.' (2003; 49). Undoubtedly, this approach brings about the necessity to furnish educational activities with exploratory, experiential and creative components, and in connection with this, to improve the educational environment accordingly. Concordantly, it can be observed that conventional and rigid understanding of museology has been succeeded by a modern and free understanding thanks to the developments in museology. The modern museology, which completed the institutionalization process in the mid-19th Century and survived till the mid-20th Century, used to manifest itself as an authoritarian structure based on collecting and exhibiting objects has now been restructured by a new approach which emphasizes the interaction with visitors since the emergence of postmodern museology in the second half of the 20th Century (Onur; 2002).

It is a common knowledge that museum education is an approach which has started to develop as a result of the cooperation between museologists and educators as from the 1950s and is based on a particular philosophy and method. When considered as an educational environment, museums with their incentive facilities that speed up learning by promoting learning-by-doing are observed to be the places with a crucial function in changing the conventional understanding of education (Onur; 2003a). It is possible to say that museum education which draws attention by adopting an approach that puts students centre stage has been developing in line with the modern understanding of education. "Learning from objects", which is an approach prioritizing creativeness and depending on senses and experiences, is one of the primary principles of museum education (Onur; 2003b). It can easily be witnessed that museum education has been adopted by many countries for in-class and out-of-school education in accordance with the lifelong learning notion.

Museum education is an interdisciplinary field of study that requires educators and museologists to collaborate. It is expected that an overall assessment is firstly needed in order for museums in the TRNC to be used as educational centres. This study aims at determining the necessary actions in order for museum education to be put into practice in the TRNC. Taking into consideration the fact that many modern countries make use of museums as a means for education actively, it is unfortunate that there are no studies yet conducted in the TRNC. Additionally, this study is of capital importance as it is one of the first studies carried out related to the use of museums as educational centres in the TRNC and it may serve as a source basis for further studies.

\section{Method}

Firstly, the literature review was completed, and then information was exchanged with experts for this descriptive study. Interviews with experts from the TRNC Ministry of National Education, Youth and 
Sports, the Directorate of Education and Training and the Office for Ancient Art and Museums affiliated to the Turkish Cypriot Ministry of Tourism, Environment and Culture were conducted and information was obtained by open-ended questions. In this study, the overall purposes and principles of the structuring of Turkish Cypriot Education System and museums affiliated to the Office for Ancient Arts and Museums of the Turkish Cypriot Ministry of Tourism, Environment and Culture have been evaluated in terms of museum education. Moreover, a study was carried out on how and under what subjects the term "museum" appears in Primary School 1st, 2nd and 3rd Grade Classes Social Studies course curriculum, which was thought to be the most suitable programme for museum education practice.

\section{Evaluation of Turkish Cypriot Education System, Primary School Programmes and Primary School Social Studies Course Curriculum in Terms of Museum Education}

It can be said that museum education is an approach which fits in Turkish Cypriot Education System with respect to its principles and structure. Investigating both the educational approaches adopted and the educational methods suggested, the general principles of the system match up with museum education approaches and methods. However, the 'museum' concept is not included in the explanations regarding the general aims and structure of the Turkish Cypriot Education System.

Within the frame of the student-centred and constructivist educational approach, the Turkish Cypriot Education System should put emphasis on the principle of 'learning by doing and experiencing' and include activities that boost mental capacity and memory in primary school programmes. Moreover, it is stated that opportunities should be provided in primary school programmes for students to criticise and question anything happening around and to attend in-school and out-of-school activities.

From museum education point of view, it is observed that educational approaches and principles embraced by primary school education programmes coincide with the fundamental principles of museum education. However, as reported by the authorities from the Directorate of Education and Training, there is nothing in the agenda regarding the application of museum education in schools in a modern sense. Experts also report that students may occasionally visit museums with their teachers, but these visits are undertaken in traditional ways and on the initiative of teachers.

When social studies course in primary schools is evaluated in terms of museum education, the skills required to be developed by students and the underlying thought of the philosophy of this course match up with the aims and the principles of museum education approach. Within this context, social studies course is considered one of the most suitable courses for museum education activities in primary school programme. The 'museum' concept was mentioned 10 times in the Primary School 1st, 2nd and 3rd Grade Classes Social Studies course curriculum which was in effect in 2010-2011 School Year and in which the museum education approach was expected to be used mostly. Moreover, the 'museum' concept was used twice only to refer to the museum visits within the scope of the programme.

Even though no studies were yet initiated in the relevant ministries and offices in the TRNC regarding the use of museums for educational purposes, studies in universities with respect to the museum education can be regarded as the first studies in this field in the TRNC. As of 2005-2006 Academic Year within the scope of Creativeness and Creative Children Activities course taught by Prof. Dr. Ayşe Çakır İlhan, Head of the Museum Education Department, Graduate School of Social Sciences, Ankara University at Preschool Teaching Department, Atatürk Faculty of Education, Near East University, museum education activities have been practised by teacher candidates. Besides these practices, within the scope of Drama course taught by the same professor, applied drama activities were held in the exhibition called 'Leonardo: The Universal Genius' in Near East University Museum on April, 2007. Then, 15 students enrolled on the course called 'Museum and Education' taught by Prof. Dr. Ayşe Çakır İlhan in Preschool Teaching Department Faculty of Education and museum education practices were conducted at graduate education level in museums in the TRNC. Moreover, within the scope of 
'Turkish Cypriot Culture' course taught by Fatma Giritli Postgraduate student in the Department of Fine Arts Education, Graduate School of Educational Sciences, Ankara University- in the TRNC Teacher Training Academy, practices regarding the use of museums in the TRNC as educational centres were conducted in 2008-2009 Academic Year. Lastly, it is also known that educational practices related to the use of museums as educational centres in the TRNC are included by Fatma Giritli and Emine Kıvanç -postgraduate students from the Department of Fine Arts Education, Graduate School of Educational Sciences, Ankara University- in their undergraduate courses in Atatürk Faculty of Education, Near East University.

When course curriculums in primary, secondary and high schools are investigated, some subjects regarding the use of museums as educational centres can be found. As for the universities, it is accepted that the use of museums for educational purposes is more essential.

\section{Recommendations}

Even though museums in the TRNC have not gone through a systematic restructuring process for educational studies yet, it is known that these museums have suitable components for museum education. Furthermore, it is a positive fact in terms of museum education that museums in the TRNC are easily accessible as the TRNC is small country. However, it is considered a major deficiency that there are no archaeologists, art historians and museum education experts employed in museums and the understanding of the museum education concept has not been completely adopted yet in the TRNC. In order for this deficiency to be corrected immediately, an educational unit within the Office for Ancient Arts and Museums, Ministry of Tourism, Environment and Culture, to which museums and sites are affiliated, should be established and all educational activities should be planned and conducted by museum education experts in these museums in collaboration with schools. With respect to both formal and informal education, each museum should be provided with a functional modern structure which is in service of society by preparing museum education leaflets according to various age groups and educational activities.

Another way of ensuring that people, who generally visit museums in childhood with school trips for the first time, leave museums with positive feelings is to abandon the traditional museum visit custom, that is, entering the museum through the front gate and leaving quickly through the back door without offering students a chance to focus on or to interact with the objects inside. One of the most important features of museum education is that it is an effective approach to arise people's interest in museums by making museum visits joyful and attractive. It is imperative to include issues about museum education in curriculums of teacher training institutions in the TRNC and to provide state school teachers with inservice training seminars on museum education by the Ministry of National Education.

In general, use of museums as educational centres in programmes, within the scope of Turkish Cypriot Education System, and the teachers who receive in-service training on museum education should be encouraged.

In order for the understanding regarding the use of museums as educational centres to be developed, the Ministry of Tourism, Environment and Culture should contribute in the awareness-raising process related to the issue by organizing conferences, symposiums, contact meetings and activity projects under the roof of the Directorate of Culture. 
